\title{
Gene expression profiles in primary duodenal chick cells following transfection with avian influenza virus H5 DNA plasmid encapsulated
} in silver nanoparticles

\author{
This article was published in the following Dove Press journal: \\ International Journal of Nanomedicine \\ 20 February 2013 \\ Number of times this article has been viewed
}

\author{
Seyed Davoud Jazayeri' \\ Aini Ideris ${ }^{1,2}$ \\ Kamyar Shameli ${ }^{3}$ \\ Hassan Moeini' \\ Abdul Rahman Omar ${ }^{1,2}$ \\ 'Institute of Bioscience, ${ }^{2}$ Faculty \\ of Veterinary Medicine, ${ }^{3}$ Faculty \\ of Science, Universiti Putra Malaysia, \\ Serdang, Selangor, Malaysia
}

\begin{abstract}
In order to develop a systemically administered safe and effective nonviral gene delivery system against avian influenza virus (AIV) that induced cytokine expression, the hemagglutinin (H5) gene of AIV, A/Ck/Malaysia/5858/04 (H5N1) and green fluorescent protein were cloned into a coexpression vector pIRES (pIREGFP-H5) and formulated using green synthesis of silver nanoparticles (AgNPs) with poly(ethylene glycol) and transfected into primary duodenal cells taken from 18-day-old specific-pathogen-free chick embryos. The AgNPs were prepared using moderated temperature and characterized for particle size, surface charge, ultraviolet-visible spectra, DNA loading, and stability. AgNPs and AgNPpIREGFP-H5 were prepared in the size range of $13.9 \mathrm{~nm}$ and $25 \mathrm{~nm}$ with a positive charge of $+78 \pm 0.6 \mathrm{mV}$ and $+40 \pm 6.2 \mathrm{mV}$, respectively. AgNPs with a positive surface charge could encapsulate pIREGFP-H5 efficiently. The ultraviolet-visible spectra for AgNP-pIREGFP-H5 treated with DNase I showed that the AgNPs were able to encapsulate pIREGFP-H5 efficiently. Polymerase chain reaction showed that AgNP-pIREGFP-H5 entered into primary duodenal cells rapidly, as early as one hour after transfection. Green fluorescent protein expression was observed after 36 hours, peaked at 48 hours, and remained stable for up to 60 hours. In addition, green fluorescent protein expression generally increased with increasing DNA concentration and time. Cells were transfected using Lipocurax in vitro transfection reagent as a positive control. A multiplex quantitative mRNA gene expression assay in the transfected primary duodenal cells via the transfection reagent and AgNPs with pIREGFP-H5 revealed expression of interleukin (IL)-18, IL-15, and IL-12 $\beta$.
\end{abstract}

Keywords: silver nanoparticles, avian influenza, hemagglutinin, transfection, primary cells

\section{Introduction}

Gene therapy offers the potential to treat several diseases using therapeutic gene-based drugs. It is essential to develop carrier systems that improve DNA vaccine efficacy. One of the requirements for successful gene therapy is the development of nontoxic and efficient carriers for gene delivery. ${ }^{1}$

Compared with viral vectors, nonviral gene carriers, such as liposomes, cationic polymers, ${ }^{2,3}$ recombinant proteins, ${ }^{4}$ and inorganic nanoparticles, ${ }^{5}$ have been widely investigated and offer the advantages of easy and large-scale production, nonimmunogenicity, and flexible DNA and RNA loading. In addition to being a biodegradable polymer, metal-based nanoparticles, in particular copper, zinc, titanium, ${ }^{6}$ magnesium, gold, ${ }^{7}$ alginate, and silver, have been developed, but silver nanoparticles
Correspondence: Abdul Rahman Omar Institute of Bioscience, Universiti Putra Malaysia 43400, Serdang, Selangor, Malaysia

Tel $+60389472 \mathrm{I}$ I I

Fax +60389472101

Email aro@ibs.upm.edu.my 
(AgNPs) have proven to be the most effective, and have found several applications. ${ }^{8}$

Several synthesis methods for preparation of AgNPs have been reported, among which chemical reduction methods are the most commonly used and require use of both a reducing and stabilizing agent. The nature and concentration of these reducing and stabilizing agents play an important role in the size, distribution, and shape of the nanoparticles, and largely determine their functional properties. ${ }^{9}$ AgNPs synthesized by various techniques have received particular attention because of their stability, easy production, and delivery, and because they are relatively inexpensive, with potential application in many fields, including sensors, catalysis, and a range of medical and drug delivery systems. ${ }^{10,11}$ Further, AgNPs have excellent biocompatibility and limited toxicity at low concentrations. ${ }^{12}$ An in vitro cytotoxicity study using MCF-7, a cancerous human cell line, demonstrated the safety of AgNPs synthesized using $\mathrm{AgNO}_{3}$, with $\beta$-D-glucose and poly(ethylene glycol) (PEG) as the reduction agent and stabilizer, respectively. In addition, an in vivo study showed that chicks inoculated orally with AgNPs remained clinically healthy and did not show a significant increase in cytokine expression, including proinflammatory cytokines. ${ }^{11}$

Spread of the highly pathogenic avian influenza virus (H5N1) remains a major global concern. ${ }^{13}$ The development of safe and efficient avian influenza vaccines for animal and human use is essential for preventing panzootic influenza and pandemics worldwide. Protective immunity against avian influenza depends largely on development of the immune response against hemagglutinin glycoprotein. ${ }^{14}$ However, the majority of vaccines require intramuscular injection and even electroporation, which could limit their application, especially in livestock. ${ }^{13}$ Our previous study showed that chickens given an oral H5 DNA vaccine using AgNPs as a carrier showed antibody and $T$ cell responses with enhanced Th1-like cytokine expression in the spleen. ${ }^{11}$ However, there is no direct evidence of specific cytokines induced by hemagglutinin of avian influenza virus.

In our previous gene expression profiling study using a multiplex quantitative mRNA gene expression assay, 18-day-old specific-pathogen-free primary chick embryo cells were not able to express proinflammatory (granulocytemacrophage colony-stimulating factor, interleukin [IL]-1 $\beta$, transforming growth factor- $\beta$, TNFSF13B, IL-12 $\beta$, IL-6, and IL-8), Th1 (interferon- $\gamma$, IL-2, IL-15, and IL-18), or Th2 (IL-4 and IL-10) cytokines upon culture (data not shown). Hence, primary cells without cytokine expression could provide the opportunity to analyze the real expression level of any transfected gene. The purpose of this study was to assess the value of AgNPs as a carrier for delivery of pIREGFP-H5 using primary duodenal cells in a chick embryo model.

\section{Materials and methods Synthesis of AgNPs using moderated temperature}

First, $10 \mathrm{~mL}$ of a $1.0 \mathrm{M}$ solution of $\mathrm{AgNO}_{3}(>99 \%$, Merck, Darmstadt, Germany) was added to $200 \mathrm{~mL}$ of a $0.10 \%$ (w/v) aqueous solution of soluble PEG (molecular weight 3350, Sigma-Aldrich, St Louis, MO, USA). After complete dissolution of the components, $20 \mathrm{~mL}$ of a $1.0 \mathrm{M}$ aqueous solution of $\beta$-D-glucose (BDH AnalaR, Darmstadt, Germany) was added, with further stirring at $45^{\circ} \mathrm{C}$ and maintenance at this temperature for 6 hours. ${ }^{11}$

\section{Methods and instruments used for characterization}

Transmission electron microscopy was carried out using a drop of aqueous solution containing the AgNPs or pIREGFPH5-loaded AgNPs (AgNP-pIREGFP-H5) placed separately on carbon-coated copper grids. The samples were dried and kept under a desiccator before being loaded onto a specimen holder. Transmission electron microscopy was carried out using a H-7100 electron microscope (Hitachi, Tokyo, Japan), and the particle size distributions were determined using the UTHSCSA Image Tool program version 3.0 (The University of Texas Health Science Center at San Antonio, San Antonio, TX, USA). Ultravioletvisible spectra were recorded over the range of 250-800 nm using an HUV 1650 PC ultraviolet-visible spectrophotometer (Shimadzu, Tokyo, Japan). To determine the particle size distribution and zeta potential, the particles were suspended in nuclease-free water and measurements were made using a Zetasizer 3000 (Malvern, Worcestershire, UK) according to the manufacturer's instructions. The average of three measurements was used and expressed as the Z-average diameter \pm standard deviation $(\mathrm{nm})$ and zeta potential \pm standard deviation $(\mathrm{mV})$.

\section{Construction of recombinant DNA plasmids}

The pIRES coexpression vector (Clontech, Mountain View, CA, USA) was used to construct a DNA plasmid with the avian influenza virus A/Ck/Malaysia/5858/04 (H5N1) H5 gene available at GenBank accession number DQ320934 (pIREGFP-H5), encoding a red-shifted variant of wild-type enhanced green fluorescent protein and $\mathrm{H} 5$ proteins. The coding sequence of the enhanced green fluorescent protein gene taken from pEGFP-N2 plasmid (Clontech) was inserted into the SalI and NotI cloning sites of the McsB of the pIRES vector 
to generate pIREGFP plasmid. The full length of the $\mathrm{H} 5$ gene was then amplified using a pair of $\mathrm{H} 5$-specific primers, ie, 5'-ACACGCTAGCACCATGGAGAAAATAGTGCTTC-3' and 5'-AGCTACGCGTTTAAATCAAATTCTGCATTG-3' and cloned into the NheI and MluI sites of the McsA of the pIREGFP plasmid, downstream of the CMV promoter, to construct pIREGFP-H5. After transformation into Escherichia coli DH5- $\alpha$, the correct orientation and nucleotide sequence of the genes inserted were verified by double-stranded sequencing. The pIREGFP and pIREGFP-H5 constructs were purified using an endotoxin-free plasmid purification kit (Qiagen, Valencia, CA, USA). The quantity and quality of the purified plasmids was assessed by optical density at $260 \mathrm{~nm}$ and $280 \mathrm{~nm}$ and by electrophoresis in 1\% agarose gel (Promega, Madison, WI, USA).

\section{Preparation of AgNP-pIREGFP-H5 plasmid complexes}

The pIREGFP-H5 plasmid expressing the avian influenza virus $\mathrm{H} 5$ gene was used for in vitro delivery of the AgNPpIREGFP-H5 complexes into primary duodenal cells. Complexes containing pIREGFP-H5 and AgNPs were prepared by conjugation following the method previously described by Jazayeri et al. ${ }^{11}$ Briefly, $10 \mu \mathrm{L}$ of extracted pIREGFP-H5 ( $200 \mathrm{ng} / \mathrm{mL}$ ) was added to $150 \mu \mathrm{L}$ of $0.1 \mathrm{M}$ phosphate-buffered saline ( $\mathrm{pH}$ 7.4). To facilitate binding between the plasmid and the nanoparticles, the mixture containing pIREGFP-H5 was added slowly to $40 \mu \mathrm{L}$ of AgNPs containing $3.7 \times 10^{-2} \mu \mathrm{g}$ of silver at a rate of $10 \mu \mathrm{L}$ per minute, under constant vortexing.

\section{Analysis of DNA band retardation}

The pIREGFP-H5 and AgNP-pIREGFP-H5 were analyzed on $1 \%$ agarose gel. In this assay, $200 \mathrm{ng}$ of DNA were loaded into the well and electrophoresis was performed at $80 \mathrm{~V}$ for 40 minutes.

\section{Protection of AgNP-pIREGFP-H5 against DNase I}

To confirm physical encapsulation of the plasmids into AgNPs, the pIREGFP-H5 and AgNP-pIREGFP-H5 were treated with 0.2 U DNase I (Vivantis, Selangor, Malaysia) following the manufacturer's protocol. The samples were then recorded over the range of 250-800 $\mathrm{nm}$ using the HUV 1650 PC ultraviolet-visible spectrophotometer.

\section{Preparation of primary chick cell culture}

Embryonic primary chick cell cultures were prepared using duodenal tissue from 18-day-old specific-pathogen-free chick embryos. ${ }^{17}$ Briefly, a chick embryo was dissected, and the duodenum was separated and cut into small pieces in phosphate-buffered saline prior to being digested with $0.25 \%$ trypsin-EDTA (Invitrogen, Wirral, UK) for 5 minutes. This procedure was repeated three times. The separated cells were then collected by centrifugation at $500 \times \mathrm{g}$ for 10 minutes at room temperature (about $25^{\circ} \mathrm{C}$ ). The cells were seeded in 12-well plates at a density of $3.5 \times 10^{5}$ cells $/ \mathrm{mL}$ in Dulbecco's modified Eagle's medium (Invitrogen, Carlsbad, CA, USA) supplemented with $10 \%$ newborn calf serum. The cells were incubated in a humidified environment at $37^{\circ} \mathrm{C}$ with $5 \% \mathrm{CO}_{2}$ throughout the experiment. Two hours prior to use, the medium was replaced with fresh Dulbecco's modified Eagle's medium without antibiotics or serum. Ethics approval was obtained from the institutional animal care and use committee at the Faculty of Veterinary Medicine, Universiti Putra Malaysia (reference number UPM/FPV/PS/3.2.1.551/ AUP-R72).

\section{In vitro delivery of AgNP-pIREGFP- H5 into primary chick cells}

A $100 \mu \mathrm{L}$ aliquot containing approximately $10^{6}$ cells $/ \mathrm{mL}$ suspension (viability and number of cells determined by trypan blue) was seeded into each well of a round-bottom 96-well plate and allowed to grow to approximately $85 \%$ confluence (about 36 hours). The cells were washed three times with prewarmed phosphate-buffered saline, and mixed with $300 \mu \mathrm{L}$ of freshly prepared serum and antibioticfree medium. Following pretreatment, $0.25-2 \mu \mathrm{g} / \mathrm{mL}$ of naked pIREGFP and pIREGFP-H5, 1.25-10 $\mu \mathrm{L}$ of AgNP-pIREGFP and AgNP-pIREGFP-H5 (containing 0.25-2 $\mu \mathrm{g} / \mathrm{mL}$ of plasmid), and 1.25-10 $\mu \mathrm{L}$ of AgNPs were added to each well. The cells were then incubated for 25 minutes at room temperature, with occasional shaking to redisperse the plasmid. Lipocurax in vitro transfection reagent (Ambo Life, Taoyuan County, Taiwan) was used as the positive control for delivery of pIREGFP and pIREGFP-H5 (Lipo-pIREGFP-H5) following the manufacturer's protocol. Expression of green fluorescent protein was visualized using a fluorescence microscope (Olympus IX 81, Tokyo, Japan).

\section{Detection of transfected pIREGFP-H5 in primary cells}

Transfected plasmid DNA with AgNPs and transfection reagent from primary duodenal cells were prepared using the GeneAll Exgene Mini genomic extraction kit (GeneAll Biotechnology Co, Ltd, Seoul, Korea) as per the manufacturer's recommendations at $1,6,12,24$, and 48 hours. The H5 gene fragment was amplified 
in a $50 \mu \mathrm{L}$ reaction containing $1.5 \mu \mathrm{L}$ of $10 \times$ polymerase chain reaction buffer, $0.6 \mu \mathrm{L}$ of $50 \mathrm{mM} \mathrm{MgCl}_{2}, 0.6 \mu \mathrm{L}$ of dNTP mix (10 mM each), $10 \mu \mathrm{L}$ of $100 \mathrm{mM}$ forward primer (5'-CCCCAAGCTTATGGAGAAAATAGTGCTT-3'), $10 \mu \mathrm{L}$ of $10 \mu \mathrm{M}$ reverse primer $\left(5^{\prime}\right.$-CCCGGAGGATCCAATG CAAATTCTGCATTGTAA-3'), $0.3 \mu \mathrm{L}$ of Taq DNA polymerase ( $5 \mathrm{U} / \mu \mathrm{L}$, Vivantis), $2 \mu \mathrm{L}$ (50 ng) of template, and $25 \mu \mathrm{L}$ of $\mathrm{dH}_{2} \mathrm{O}$. Amplification was performed using the following parameters: one cycle of $94^{\circ} \mathrm{C}$ for 5 minutes; 30 cycles of $94^{\circ} \mathrm{C}$ for one minute; $56.9^{\circ} \mathrm{C}$ for one minute; $72^{\circ} \mathrm{C}$ for 2 minutes; a final extension step of $72^{\circ} \mathrm{C}$ for 10 minutes; and a hold cycle at $4^{\circ} \mathrm{C}$.

\section{Preparation of total RNA from duodenal cells}

Total RNA was isolated from the cultured cells using Trizol reagent (GeneAll-Korea) following the manufacturer's protocol. Uninfected cells were processed in parallel as a negative control. Quantification and the integrity of the RNA extracted was carried out using a NanoDrop ND-1000 instrument (Thermo Scientific, Waltham, MA, USA) and Bioanalyzer chips (Agilent Technologies, Santa Clara, CA, USA).

\section{Multiplex quantitative cytokine expression study}

Multiplex gene expression profiling of the chick cytokines was performed using the GenomeLab Genetic Analysis System (GeXP, Beckman Coulter, Fullerton, CA, USA) as recently described by Jazayeri et al. ${ }^{11,16}$ Briefly, expression of 13 proinflammatory cytokines (granulocyte-macrophage colony-stimulating factor, IL-1 $\beta$, transforming growth factor- $\beta$, TNFSF13B, IL-12 $\beta$, IL-6 and IL-8), Th1 (interferon- $\gamma$, IL-2, IL-15, IL-18), and Th2 (IL-4 and IL-10) cytokines was measured in primary cells transfected with the plasmids. COL6A2 was used as a housekeeping gene to normalize the relative gene expression by dividing the peak area of each gene by the peak area of the COL6A2 gene.

\section{Statistical analysis}

The results were analyzed using one-way analysis of variance and tested by Duncan's multiple range test to determine any differences between treatment means at the 5\% $(P \leq 0.05)$ significance level. The data were statistically analyzed using the Statistical Package for the Social Sciences (SPSS Inc, Chicago, IL, USA).

\section{Results}

The AgNPs were prepared using a moderated temperature and with PEG and $\beta$-D-glucose as the stabilizer and reduction agent, respectively. Figure 1A shows the nature of the interaction between the charged AgNPs and PEG. As shown in Figure 1B, the ultraviolet-visible spectra of the plasmid DNA and AgNPs peaked at $262 \mathrm{~nm}$ and $417 \mathrm{~nm}$, respectively, whereas the nanoencapsulated plasmid showed two peaks at $262 \mathrm{~nm}$ and $422 \mathrm{~nm}$. After treatment with DNase I, no peak was recorded for the plasmid, while two peaks were detected for the plasmid-AgNPs complex at $262 \mathrm{~nm}$ and $445 \mathrm{~nm}$, indicating that the cationic AgNPs is an excellent scaffold which protects DNA from digestion by DNase I.

\section{Characterization of nanoparticles}

Transmission electron microscopy was used to observe the morphology and distribution of the AgNPs and AgNP-pIREGFP-H5 complexes. AgNPs and AgNPpIREGFP-H5 showed a uniform shape with a maximum size of $13 \pm 2.9 \mathrm{~nm}$ and $25 \pm 7 \mathrm{~nm}$ (with lower frequency), respectively (Figure 2). The zeta potential of the AgNPs and AgNPpIREGFP-H5 complexes was $+78 \pm 0.6$ and $+40 \pm 6.2 \mathrm{mV}$, respectively. The mean particle diameter of the AgNPs and AgNP-pIREGFP-H5 obtained from the zeta potential were in agreement with our findings from transmission electron microscopy (data not shown).

\section{Preparation of AgNP-pIREGFP-H5 complexes}

Because the negative charge on the phosphate groups of the DNA backbone is masked after electrostatic binding to the positive charge of PEG, once successfully complexed, the DNA loses its ability to migrate to the anode during agarose gel electrophoresis. Therefore, AgNP-pIREGFP-H5 was considered to be successfully complexed when full retardation of the DNA band in 1\% agarose gel was observed (Figure 3).

\section{Construction of plasmids}

The avian influenza virus A/Ck/Malaysia/5858/04 (H5N1) H5 and enhanced green fluorescent protein were amplified and cloned into the coexpression vector pIRES to construct pIREGFP-H5. The final construct is shown in Figure 4A. Successful insertion of the genes was confirmed by double digestion of the construct with NotI and SalI for green fluorescent protein and NheI and MulI for H5, as shown in Figure 4B.

\section{Transfection of pIREGFP-H5 plasmid into primary duodenal cells}

Primary duodenal cells from 18-day-old chick embryos were used as a model cell line to study the in vitro transfection efficiency of AgNP-pIREGFP-H5 in comparison with 
A

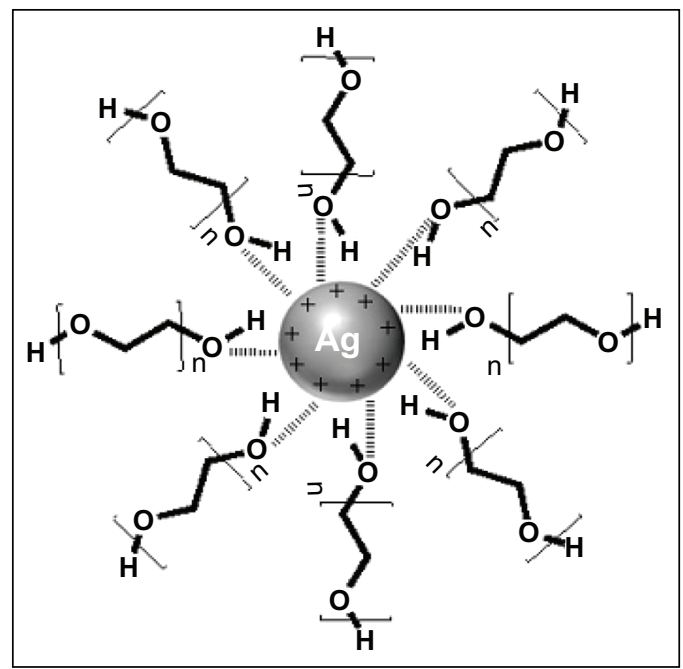

B

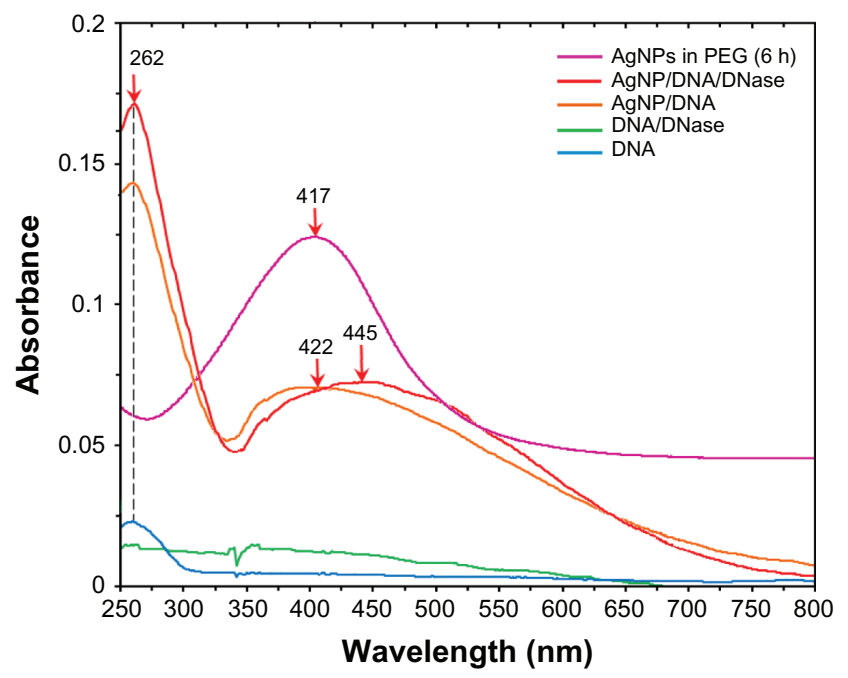

Figure I (A) Schematic depiction of the chemical structure of silver coated nanoparticles with PEG showing the interactions between hydroxyl groups in PEG with the positive charge on the surface of AgNPs (AgNP-PEG). (B) Ultraviolet-visible spectra of DNA, DNA-DNase, AgNP-DNA, AgNP-DNA-DNase, and AgNPs. Abbreviations: AgNPs, silver nanoparticles; PEG, poly(ethylene glycol).
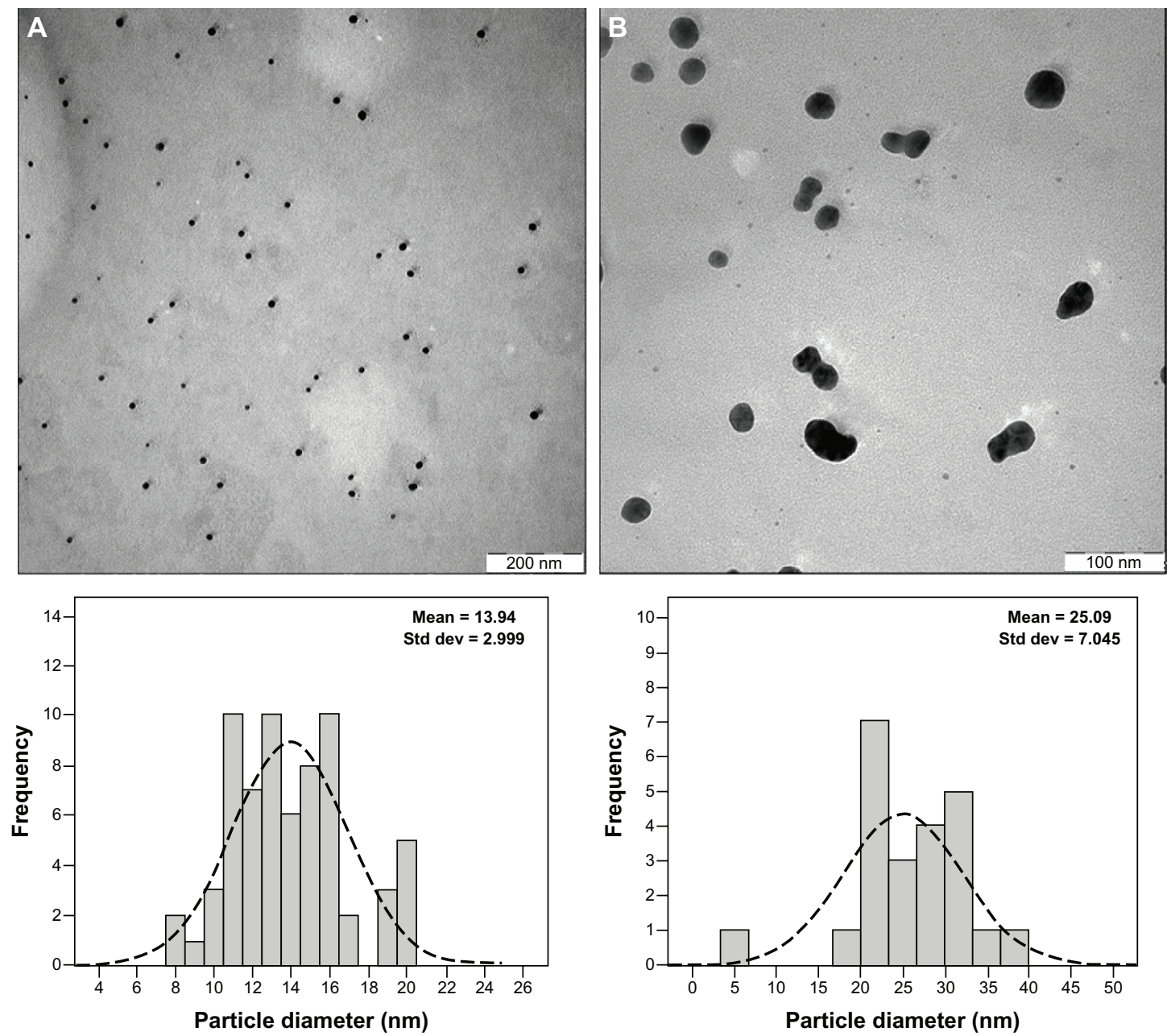

Figure 2 Physical characteristics of synthetic particles and mediator encapsulation. Transmission electron microscopic image and corresponding particle size and distribution of (A) AgNPs (after 6 hours) and (B) AgNP-pIREGFP-H5.

Abbreviation: AgNPs, silver nanoparticles. 


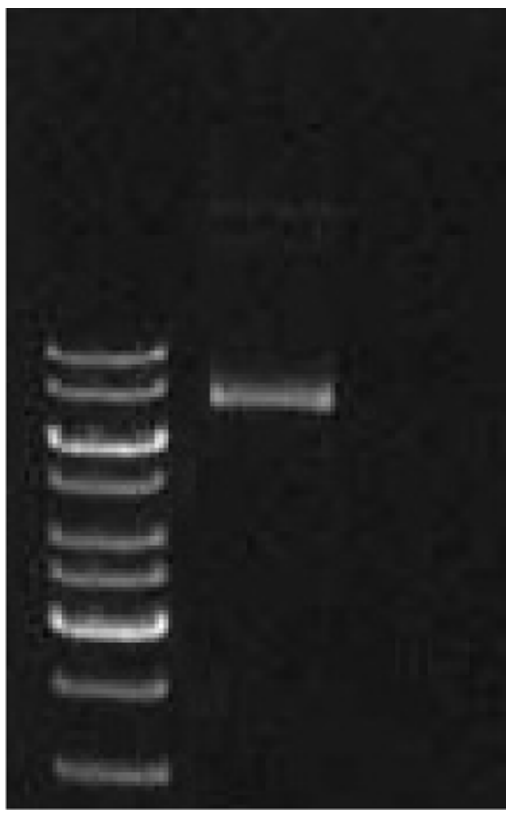

Figure 3 DNA band retardation analysis.

Notes: Binding of DNA to AgNPs masks the negative charges in the DNA backbone which facilitates its migration during gel electrophoresis. Gel migration of pIREGFP-H5 complexed with cationic AgNPs was completely abolished. Equal amounts of naked pIREGFP-H5 (200 ng) were loaded on I\% agarose gel. I kb DNA ladder plus marker (Fermentas, Lithuania).

Abbreviation: AgNPs, silver nanoparticles.

delivery of the naked plasmid DNA using the commercially available Lipocurax in vitro transfection reagent. Green fluorescent protein expression was detected by fluorescence microscopy in cells transfected with pIREGFP-H5 at all concentrations $(0.25-2.0 \mu \mathrm{g} / \mathrm{mL})$ and time points. The green color in Figure 5 indicates successful transfection of plasmid by both the AgNPs and the transfection reagent after 36 hours at all concentrations, but the cells inoculated with $0.25-0.5 \mu \mathrm{g} / \mathrm{mL}$ plasmid showed weaker fluorescence (data not shown) compared with those inoculated with the $1-2 \mu \mathrm{g} / \mathrm{mL}$ concentration (Figure 5). More green fluorescent protein expression was indicated by the greater number of more brightly fluorescent cells detected after 48 hours of transfection using both delivery methods. An increase in green fluorescent protein expression and fluorescence intensity was detected with increasing the plasmid concentration and a longer incubation time up to 48 hours. However, 60 hours after transfection, the number of dead nontransfected and transfected cells increased (data not shown), probably because of the limited supply of nutrients in the medium.

\section{Detection of H5 in primary duodenal cells}

Plasmids were extracted from the transfected primary duodenal cells using AgNPs and transfection reagent, and polymerase chain reaction was used to confirm the presence of the $\mathrm{H} 5$ gene in the cells. As shown in Figure 6, the H5 gene was successfully detected one hour after transfection for up to 48 hours.

\section{Analysis of cytokine expression}

Multiplex gene expression profiling was used to measure the relative expression of different cytokines in the transfected
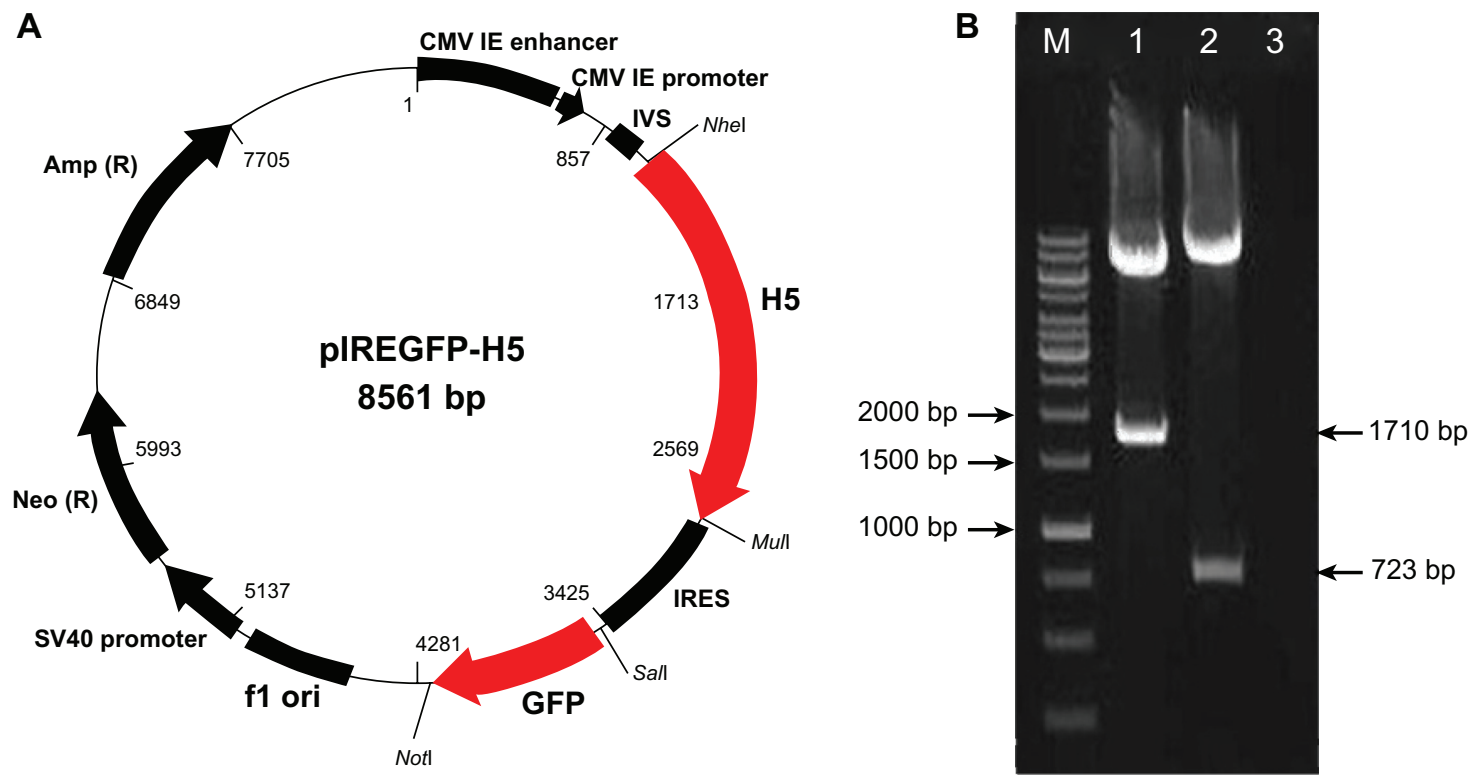

Figure 4 (A) Map of DNA plasmid pIREGFP-H5. The construct was generated by the insertion of the enhanced GFP gene from pEGFP-N2 into the Sall and Notl sites of the expression vector and $\mathrm{H} 5$ gene into the Nhel and Mull sites, downstream of the CMV promoter. (B) Double digestion analysis of pIREGFP-H5 with (I) Notl and Sall and (2) Nhel and Mull. $M=I$ kb DNA ladder plus marker (Fermentas, Lithuania).

Abbreviation: GFP, green fluorescent protein. 

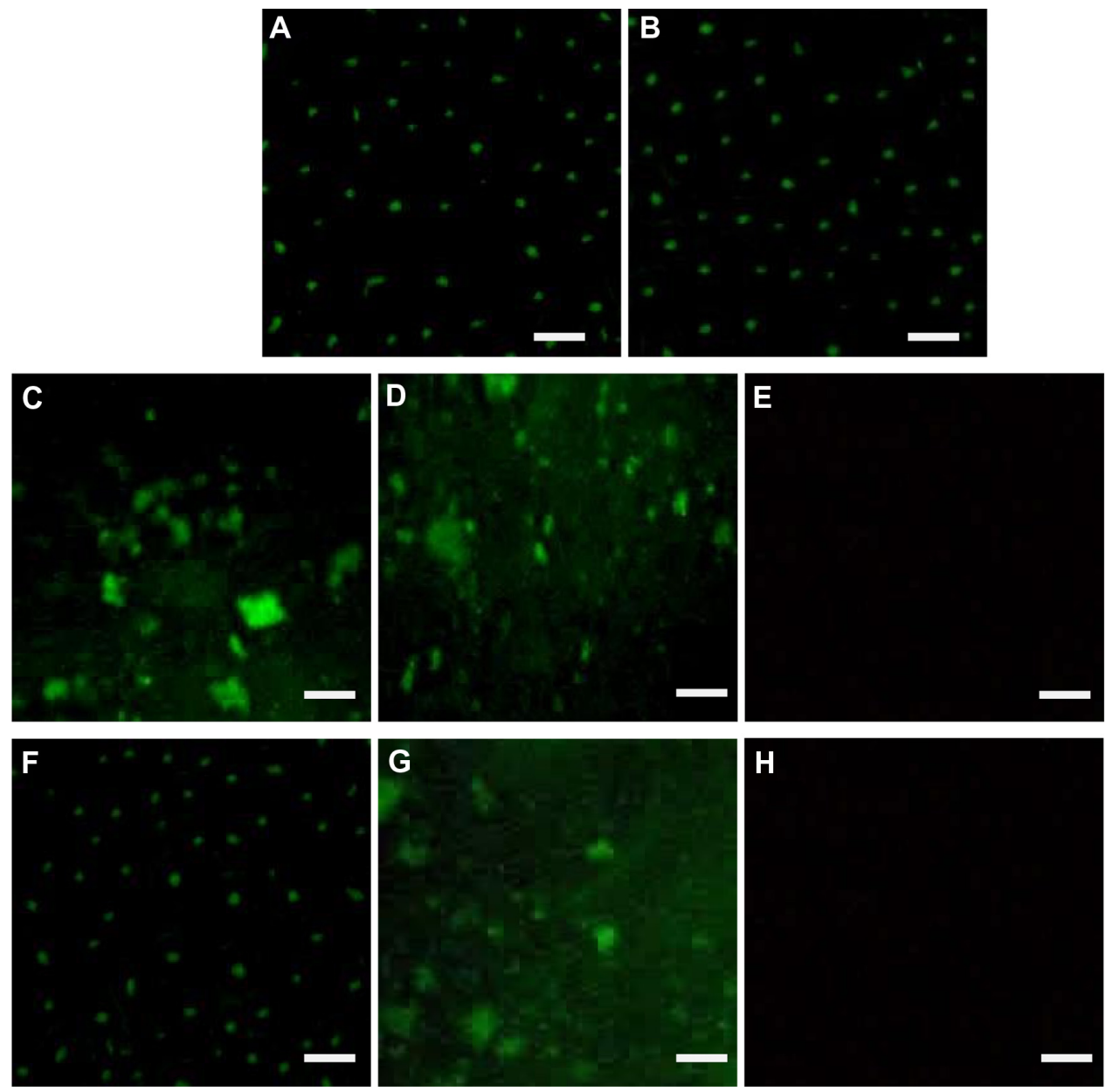

Figure 5 Fluorescence microscopic images of primary cells transfected with pIREGFP-H5. Primary duodenal cells were transfected by AgNPs and transfection reagent, and enhanced GFP was then monitored by fluorescence microscopy. (A) Primary cells transfected with $10 \mu \mathrm{L}$ of AgNP-plREGFP-H5 after 36 hours, (B) $20 \mu \mathrm{L}$ of AgNPpIREGFP-H5 after 36 hours, (C) $10 \mu \mathrm{L}$ AgNP-pIREGFP-H5 after 48 hours, (D) $20 \mu \mathrm{L}$ of AgNP-pIREGFP-H5 after 48 hours, (E) naked pIREGFP-H5 without any delivery complex, (F) $10 \mu \mathrm{L}$ of Lipo-pIREGFP-H5 after 36 hours, (G) $10 \mu \mathrm{L}$ of Lipo-pIREGFP-H5 after 48 hours, and (H) naked pIREGFP-H5 without any delivery complex.

Note: The white bar in each image represents $2 \mu \mathrm{m}$, magnification 40x.

Abbreviation: AgNPs, silver nanoparticles.

primary duodenal cells. There was no cytokine expression recorded in the cultured embryonic duodenal chick cells before inoculation. Inoculation of these cells with naked plasmids (pIREGFP and pIREGFP-H5) as well as AgNPpIREGFP, Lipo-pIREGFP and AgNPs alone resulted in no cytokine expression for up to 48 hours (Figure 7), but

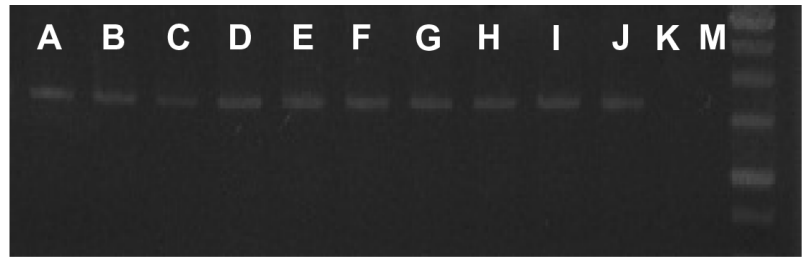

Figure 6 Polymerase chain reaction amplification of $\mathrm{H} 5$ from primary duodenal cells after transfection with AgNPs at I (A), 6 (B), 12 (C), 24 (D), and 48 (E) hours, and transfection reagent at I (F), 6 (G), 12 (H), 24 (I), and 48 (J) hours, respectively, with a $(\mathbf{K})$ negative control.

Note: $M=$ I kb DNA ladder plus marker (Fermentas, Lithuania). inoculation of the cells with AgNP-pIREGFP-H5 and LipopIREGFP-H5 induced expression of IL-18, IL-15 and IL-12 $\beta$ after 36 and 48 hours. Expression levels for all cytokines in cells inoculated with AgNP-pIREGFP-H5 were similar to those of the cells inoculated with Lipo-pIREGFP-H5 $(P>0.05)$, with IL-18 showing the highest expression (Figure 7).

\section{Discussion}

Green synthesis of AgNPs using $\beta$-D-glucose and PEG as the reduction agent and stabilizer, respectively, is an attractive and unique delivery method for oral DNA vaccination. These nanoparticles are stable, easy to produce and deliver, relatively inexpensive to produce on a large scale, have low toxicity, and are able to induce robust immune responses. ${ }^{11}$ In this study, we investigated the feasibility of conjugation and protection of a plasmid using 


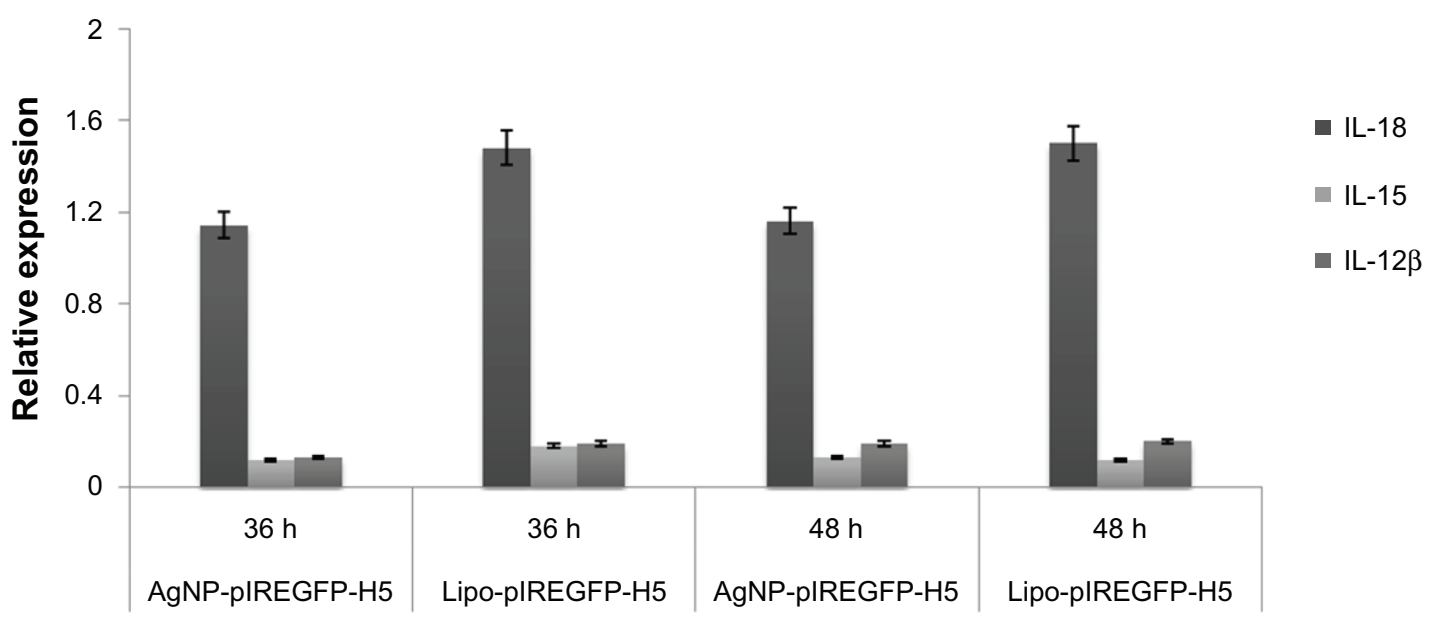

Figure 7 Relative expression levels of cytokine genes in primary chick cells transfected with AgNP-H5 and Lipo-H5.

Notes: Transfection of primary cells with naked plasmids (pIREGFP and pIREGFP-H5) as well as AgNP-pIREGFP, Lipo-pIREGFP, and AgNPs showed no cytokine expression for up to 48 hours (data not shown). Each value represents the mean \pm standard deviation of three samples. Data were normalized to the COL6A2 gene.

a silver-based nanoparticle surface. We also investigated the ability of AgNPs to mediate H5 DNA vaccine transfection and cytokine expression in primary duodenal cells from specific-pathogen-free chick embryos.

Consistent with our previous study, by increasing the reaction time until 48 hours, the mean diameter of the AgNPs increased gradually up to $25 \mathrm{~nm}$, suggesting that by increasing the duration of the reaction in the presence of PEG, the stability of the AgNPs decreased considerably. Hence, after 6 hours of incubation, stable AgNPs colloids with a good distribution and uniform particle size could be obtained. ${ }^{11}$

The AgNPs and AgNP-pIREGFP-H5 had a mean size of $13 \pm 2.9 \mathrm{~nm}$ and $25 \pm 7 \mathrm{~nm}$, with a positive charge of $+78 \pm 0.6 \mathrm{mV}$ and $+40 \pm 6.2 \mathrm{mV}$, respectively. Further, the size of the nanoparticles and their zeta potential (which defines the average electrical potential at a hydrodynamic slip plane adjacent to a solid surface exposed to a liquid) are also very important for favorable cellular uptake.

However, in this study, the high positive charge on the AgNP-pIREGFP-H5 surface made it more likely to adhere to the cell membrane and interfere with cellular function. ${ }^{18}$ The size of the nanoencapsulated plasmid is dictated by several parameters that influence the particle formation mechanism, eg, the G-C versus A-T content and the degree of topological purity of the plasmid suspension. ${ }^{19}$ It has been suggested that particles less than about $150 \mathrm{~nm}$ in diameter are preferred for endocytosis. ${ }^{3,20}$ AgNPs can be coated with PEG to aid their internalization into target cells. ${ }^{21}$ These AgNPs polycations are able to condense large genes into compact structures and mask the negative DNA charges necessary when transfecting most types of cells. It is likely that a condensed DNA vector complex with a slightly positive charge could interact electrostatically with the cell membrane and thereby be internalized. The high cationic charge density on the AgNPs can act as an endosomal buffering system, thereby suppressing endosomal enzyme activity and protecting the DNA from degradation. The high cationic charge mediates both DNA condensing and buffering capacity, and reduces the need for addition of endosomolytic agents. Lysosomal membranes contain V-ATPases, which pump $\mathrm{H}^{+}$at the expense of ATP. It has been hypothesized that the increased chloride ion concentration in turn increases lysosomal osmolarity, with water entering in to relieve the gradient, resulting in lysosomal swelling and bursting, ${ }^{22}$ along with release of their expression plasmids. By a hitherto unknown mechanism, these plasmids cross the vesicular membrane and reach the cell nucleus of the host cell in which they are expressed. ${ }^{23}$ DNA adsorbed onto the surface of cationic microparticles and nanoparticles has previously been reported to enhance DNA delivery. ${ }^{24,25}$ However, in our study, colloidal stabilization of AgNP-PEG is likely to have occurred because of the presence of van der Waals forces between the negatively charged oxygen groups present in the molecular structure of PEG (Figure 1A) and the positively charged groups that surround the surfaces of the inert AgNPs. ${ }^{26}$ Overall, binding of DNA to cationic AgNPs enables substantial protection of the DNA for potential application in gene therapy and gene engineering.

He et $\mathrm{al}^{27}$ have previously reported that aminefunctionalized silica nanoparticles bound to DNA can slow 
down or inhibit DNase I activity. To investigate whether AgNPs efficiently protect DNA from enzyme cleavage, the pIREGFP-H5 plasmid and AgNP-pIREGFP-H5 complexes were treated with DNase I and then tested by ultravioletvisible spectrophotometry, which showed that AgNPs are able to cover and protect the plasmid against DNase I. According to Deaton et al, ${ }^{28}$ the average DNA fragment size of DNA digested with DNase I is around 50 base pairs, which is not able to show peaks as high as the original DNA.

Our previous studies have shown that oral delivery of DNA vaccine (pcDNA3.1/H5) using AgNPs can be detected in primary duodenal cells from the specific-pathogen-free chick embryo as early as one hour after immunization. ${ }^{11}$ The same in vitro results were obtained with AgNP-pIREGFP-H5, although green fluorescent protein expression was only detected after 36 hours. Cheng et $\mathrm{al}^{29}$ suggested that the hemagglutinin of influenza A/Vietnam/1203/2004 (H5N1) protein and its interaction with the viral neuraminidase protein plays a role in triggering the cytokine response, although the full implications of cytokine induction in vaccine virus-induced immune responses remain to be explored. Gene expression studies in specific-pathogen-free chickens vaccinated orally with Salmonella and AgNPs bearing H5 genes of the influenza virus have shown upregulated expression of IL-1 $\beta$, (a proinflammatory cytokine), IL-12 $\beta$, IL-15, and IL-18 (Th1 cytokines), and TNFSF13B. ${ }^{11,16}$ Using a sensitive multiplex gene expression assay of primary duodenal cells transfected with $\mathrm{H} 5$, there was expression of IL-12 $\beta$, IL-15, and IL-18 but no expression was recorded from the naked DNA, Lipocurax in vitro transfection reagent, AgNPs, AgNP-pIREGFP, or Lipo-pIREGFP. Hence, this study further supports the potential use of AgNPs as a carrier for oral DNA vaccination against avian influenza virus in chicks. Another study is now underway to determine the mechanisms by which the $\mathrm{H} 5$ gene and its protein induce Th1 cytokines.

The cytotoxicity of vectors used in gene therapy is an important consideration, especially when polycations with a high positive charge are used beyond certain limits, which of course depends on the type of carrier or vector used. ${ }^{30,31}$ One of the mechanisms of AgNPs cytotoxicity is its relationship with reactive oxygen species inducing apoptotic and necrotic cell death. ${ }^{32}$ Induction of proinflammatory cytokines, such as IL-1, IL-6, and tumor necrosis factor, is also thought to be associated with cytotoxicity. ${ }^{33}$ However, in the present study, no expression of IL-1 and IL-6 was found following inoculation of primary cells with naked plasmids (pIREGFP and pIREGFP-H5) or with AgNPs, AgNP-pIREGFP, or Lipo-pIREGFP.

\section{Conclusion}

Successful delivery of the green fluorescent protein gene to primary cells in this study demonstrates that AgNPs can be used for fast, safe, protective, and effective nonviral delivery of genes to cell lines.

\section{Acknowledgment}

This study was supported by an Institute of Bioscience, Higher Institution Centre of Excellence (IBS HICoE) grant from the Ministry of Higher Education, Government of Malaysia.

\section{Disclosure}

The authors report no conflicts of interest in this work.

\section{References}

1. Breyer B, Jiang W, Cheng H, et al. Adenoviral vector-mediated gene transfer for human gene therapy. Curr Gene Ther. 2001;1: 149-162.

2. Luo D, Saltzman WM. Enhancement of transfection by physical concentration of DNA at the cell surface. Nat Biotech. 2000;18: 893-895.

3. Leong KW. Polymeric controlled nucleic acid delivery. MRS Bull. 2005;30:640-646.

4. Dietz GPH, Bahr M. Delivery of bioactive molecules into the cell: the Trojan horse approach. Mol Cell Neurosci. 2004;27:85-131.

5. Xu ZP, Zeng QH, Lu, GQ, et al. Inorganic nanoparticles as carriers for efficient cellular delivery. Chem Eng Sci. 2006;61:1027-1040.

6. Schabes-Retchkiman PS, Canizal G, Herrera-Becerra R, Zorrilla C, Liu HB, Ascencio JA. Biosynthesis and characterization of Ti/Ni bimetallic nanoparticles. Opt Mater. 2006;29:95-99.

7. Gu H, Ho PL, Tong E, Wang L, Xu B. Presenting vancomycin on nanoparticles to enhance antimicrobial activities. Nano Lett. 2003;3: 1261-1263.

8. Kearns GJ, Foster EW, Hutchison JE. Substrates for direct imaging of chemically functionalized $\mathrm{SiO}_{2}$ surfaces by transmission electron microscopy. Anal Chem. 2006;78:298-303.

9. Pinto VV, Ferreira MJ, Silva R, Santosc HA, Silva F, Pereira CM. Long time effect on the stability of silver nanoparticles in aqueous medium: effect of the synthesis and storage conditions. Colloids Surf A Physicochem Eng Asp. 2010;364:19-25.

10. Skotland T, Iversen TG, Sandvig K. New metal-based nanoparticles for intravenous use: requirements for clinical success with focus on medical imaging. Nanomed Nanotechnol. 2010;6:730-737.

11. Jazayeri SD, Ideris A, Zakaria Z, Shameli K, Hassan Moeini, Omar AR. Cytotoxicity and immunological responses following oral vaccination of nanoencapsulated avian influenza virus H5 DNA vaccine with green synthesis silver nanoparticles. J Control Release. 2012;161: 116-123.

12. Zhang L, Shen YH, Xie AJ, Li SK, Jin BK, Zhang QF. One-step synthesis of monodisperse silver nanoparticles beneath vitamin $\mathrm{E}$ Langmuir monolayers. J Phys Chem B. 2006;110:6615-6620.

13. Swayne DE, Kapczynski DR. Strategies and challenges for eliciting immunity against avian influenza virus in birds. Immunol Rev. 2008;225: 314-331.

14. Lei H, Sheng Z, Ding Q, et al. Evaluation of oral immunization with recombinant avian influenza virus HA1 displayed on the Lactococcus lactis surface and combined with the mucosal adjuvant cholera toxin subunit B. Clin Vaccine Immunol. 2011;18:1046-1051.

15. Yang DG, Chung YC, Lai YK, Lai CW, Liu HJ, Hu YC. Avian influenza virus hemagglutinin display on baculovirus envelope: cytoplasmic domain affects virus properties and vaccine potential. Mol Ther. 2007;15: 989-996. 
16. Jazayeri SD, Ideris A, Zakaria Z, Yeap SK, Omar AR. Improved immune responses against avian influenza virus following oral vaccination of chickens with HA DNA vaccine using attenuated Salmonella typhimurium as carrier. Comp Immunol Microbiol Infect Dis. 2012;35:417-427.

17. Barrow PA, Lovell MA. Invasion of Vero cells by Salmonella species. J Med Microbiol. 1989;28:59-67.

18. Xu ZP, Walker TL, Liu KL, Cooper HM, Lu GM, Bartlett PF. Layered double hydroxide nanoparticles as cellular delivery vectors of supercoiled plasmid DNA. Int J Nanomedicine. 2007;2:163-174.

19. Samson J, Piscopo I, Yampolski A, et al. Fabrication of size-tunable metallic nanoparticles using plasmid DNA as a biomolecular reactor. Nanomaterials. 2011;1:64-78.

20. Prabha S, Zhou WZ, Panyam J, et al. Size-dependency of nanoparticle-mediated gene transfection: studies with fractionated nanoparticles. Int J Pharm. 2002;244:105-115.

21. Tiwari PM, Vig K, Dennis VA, Singh SR. Functionalized gold nanoparticles and their biomedical applications. Nanomaterials. 2011;1:31-63.

22. Hosseinkhani H, Tabata Y. Self assembly of DNA complexes with polycations for the delivery of genetic materials into cells. J Nanosci Nanotechnol. 2006;6:1-9.

23. Weiss S, Chakraborty T. Transfer of eukaryotic expression plasmids to mammalian host cells by bacterial carriers. Curr Opin Biotechnol. 2001; $12: 467-472$

24. Harcourt JL, Anderson LJ, Sullender W, Tripp RA. Pulmonary delivery of respiratory syncytial virus DNA vaccines using macroaggregated albumin particles. Vaccine. 2004;22:2248-2260.
25. Minigo G, Scholzen A, Tang CK, et al. Poly-l-lysine-coated nanoparticles: a potent delivery system to enhance DNA vaccine efficacy. Vaccine. 2007;25:1316-1327.

26. Silva EC, Silva MGA, Meneghetti SMP. Synthesis of colloids based on gold nanoparticles dispersed in castor oil. J Nanopart Res. 2008;10:201-208.

27. He XX, Wang KM, Tan WH. Bioconjugated nanoparticles for DNA protection from cleavage. J Am Chem Soc. 2003;125:7168-7169.

28. Deaton R, Chen J, Kim JW, Garzon MH, Wood DH. Test tube selection of large independent sets of DNA oligonucleotides. Nanotech: Sci Comput. Heidelberg, Germany: Springer; 2006:147-161.

29. Cheng X, Xu Q, Song E, Yang CF, Kemble G, Jin H. The hemagglutinin protein of influenza A/Vietnam/1203/2004 (H5N1) contributes to hyperinduction of proinflammatory cytokines in human epithelial cells. Virology. 2010;406:28-36.

30. Slita AV, Kasyanenko NA, Nazarova OV, et al. DNA-polycation complexes: effect of polycation structure on physico-chemical and biological properties. J Biotechnol. 2007;127:679-693.

31. Fischer D, Li Y, Ahlemeyer B, et al. In vitro cytotoxicity testing of polycations: influence of polymer structure on cell viability and hemolysis. Biomaterials. 2003;24:1121-1131.

32. Foldbjerg R, Olesen P, Hougaar M, Dang DA, Hoffmann HJ, Autrup H. PVP-coated silver nanoparticles and silver ions induce reactive oxygen species apoptosis and necrosis in THP-1 monocytes. Toxicol Lett. 2009;190:156-162.

33. Oh WK, Kim S, Choi M, et al. Cellular uptake, cytotoxicity, and innate immune response of silica-titania hollow nanoparticles based on size and surface functionality. ACS Nano. 2010;4:5301-5313.
International Journal of Nanomedicine

\section{Publish your work in this journal}

The International Journal of Nanomedicine is an international, peerreviewed journal focusing on the application of nanotechnology in diagnostics, therapeutics, and drug delivery systems throughout the biomedical field. This journal is indexed on PubMed Central, MedLine, CAS, SciSearch $\AA$, Current Contents ${ }^{\circledR} /$ Clinical Medicine,

\section{Dovepress}

Journal Citation Reports/Science Edition, EMBase, Scopus and the Elsevier Bibliographic databases. The manuscript management system is completely online and includes a very quick and fair peer-review system, which is all easy to use. Visit http://www.dovepress.com/ testimonials.php to read real quotes from published authors. 